\title{
A New Model Approach for Vulnerability to Assess Seawater Intrusion Risk for Monastir Aquifer System, Tunisia
}

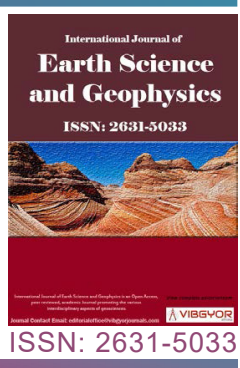

\section{Rihem Mejdoub El Fehri ${ }^{* *}$, Ranya Chrigui ${ }^{2}$, Lamia Kouzana ${ }^{1}$ and Mahmoud Dlala ${ }^{1}$}

${ }^{1}$ Department of Geology, Faculty of Sciences of Tunis, Laboratory of Hazardous and Natural Risques, University of Tunis El Manar, Tunis, Tunisia

${ }^{2}$ High National School of Engineering of Tunis, Geotechnical Engineering and Georisk Laboratory, University of Tunis El Manar, Tunis, Tunisia

\begin{abstract}
This paper presents the theory and application of a new vulnerability method (RIHM). The method is applied on Monastir shallow aquifer system, Tunisia. The results have been concluded from other established vulnerability assessment methods DRASTIC, SINTACS and GALDIT. As known, DRASTIC and SINTACS methods are not designed for seawater intrusion contamination but are useful to build the new model approach to assess groundwater vulnerability to seawater intrusion. RIHM parameters have been concluded after performed sensitivity analysis of the most important parameters of each method. Its vulnerability data are rated into four classes and assigned equal values ranging from less than 109 to 176 . These classes and ranges include: < 109 low, 109-123 moderate, 123-151 high and 151-176 very high vulnerability in all the coastal area extended for more than $2 \mathrm{~km}$ inlands. The low to moderate vulnerability is for areas with higher vadose thickness. RIHM index (RI) is also compared, and hence evaluated and verified with field data of electrical conductivity (EC) and TDS distributions. RI validation shows the advantages of RIHM method in assessing seawater intrusion with few critical parameters considered indispensable for sustainable land use planning and groundwater management of Monastir shallow aquifer system. This original study is a useful way to protect water resources considering its importance for the development of the country, and it helps decision makers to take action for groundwater management.
\end{abstract}

\section{Keywords}

Vulnerability, Sensitivity analysis, RIHM, Monastir, Tunisia

\section{Introduction}

In semiarid areas, water demands in summer seasons are almost exclusively from groundwater resources. This behavior assumes the contamination of aquifer by salinization [1]. Generally, salinization of groundwater is a result for numerous processes such as seawater intrusion, migration of saline water, evaporation, dissolution of minerals, mixing and pollution resulting from industrial, municipal, and agricultural activities [2]. The crucial issues of the over-exploitation in costal aquifer are generally delicate because they associate the notion of quantity with that of quality [3]. Seawater intrusion along irregular coastlines and under offshore

\footnotetext{
*Corresponding author: Rihem Mejdoub El Fehri, Department of Geology, Faculty of Sciences of Tunis, Laboratory of Hazardous and Natural Risques, University of Tunis El Manar, Tunis, Tunisia

Accepted: August 02, 2021; Published: August 04, 2021

Copyright: (C) 2021 El Fehri RM, et al. This is an open-access article distributed under the terms of the Creative Commons Attribution License, which permits unrestricted use, distribution, and reproduction in any medium, provided the original author and source are credited.
}

El Fehri et al. Int J Earth Sci Geophys 2021, 7:047

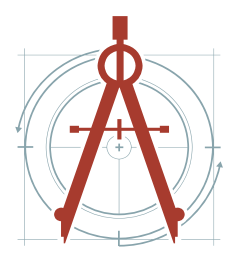


islands is a classical result of excessive noncontrolled groundwater exploitation. Moreover, the extensive pumping of coastal wells, freshwater porous aquifer and the contamination by sebkhas contribute to the seawater intrusion into mainland and are main factors in degradation of groundwater quality too $[4,5]$. Nowadays, human is restricted to change cultivation of other crops more resistant to salts since most of their wells become totally unserviceable and the land dependent on them become barren [6]. Many of Mediterranean countries have an extension of seawater intrusion in its coastal aquifer systems for example the highlighting of the marine intrusion in El Jadida groundwater, Morocco [7]. The coastal sectors of the region, especially those in the south-western part, are the most sensitive to marine intrusions which are favored by an important permeability of the Plioquaternary sandstone. This study has highlighted the marine intrusion caused by too much exploitation of the coastal aquifer. In the same country, the groundwater of coastal aquifer of Chaouia is an aquifer system formed by PlioQuaternary. The application of GALDIT identified it as a highly vulnerable aquifer with a seawater intrusion of about $3 \mathrm{~km}$ towards in almost the entire coastal area taken into consideration [8]. While in Tunisia, the availability of freshwater has an unequal geographical distribution. It plays an important role for meeting out the demand and socioeconomic developments. It needs to be protected from increasing threats of aquifer contamination especially along the coastal area [9]. Monastir aquifer system in the central-eastern coastal part of Tunisia is over exploited during the last few years. In addition to that, large numbers of inhabitant for more than 93 306hab and huge development in all economic sectors have led to seawater intrusion. The economy of Monastir is mainly based on agriculture essentially the olive cultivation for more than $85 \%$ of its area. Few years ago, the city has developed the bio-agriculture in Jammal, Moknine, Zeramdine, Béni Hassan, Ksibet Mediouni and Bembla, where two units are interested in the extraction of oil from the seeds of the prickly pear and the third is specialized in the manufacture and preservation of jam of prickly pear, carob and dates. While, industrial activities are represented essentially by European textiles factories located mainly around Ksar Hellal and Bembla. These cities cover $83 \%$ of the industrial jobs in the region. Other sectors of the economy include fishing with the fishing ports of Monastir, Ksibet elMédiouni, Sayada, Teboulba and Bekalta.Tourism sector covered $12 \%$ from the national capacity. The study area is affected by many pollution sources like industrial and urban pollution [10] inhered to enlargement of seawater intrusion. That's why, it is necessary to assess groundwater vulnerability for sustainable planning of development for this study area. As soon as, Margat announced an alertness of groundwater contamination, the groundwater vulnerability theory was introduced in France [11]. Groundwater vulnerability is an evaluation for the degree of pollutants diffusion into the hydrological settings of an aquifer to protect it for future uses [12]. View the parameters take it in consideration, it is classified into intrinsic and specific vulnerability [13]. Intrinsic vulnerability can be defined as the ease with which a contaminant introduced into the ground surface can reach and diffuse in groundwater. Specific vulnerability is used to define the vulnerability of groundwater to particular contaminants. Those parameters determine its limits and characteristics to handle good groundwater quality and to be as a wall in front of imposed contaminant load such as surface disposal of solid, liquid wastes, discharge of sewerage, and salt water intrusion [14]. To evaluate aquifer vulnerability, there are process-based, statistical, overlay and index methods [15]. The vulnerability indexmapping was used to assess the vulnerability of groundwater to potential sources of contamination and also those predicted for future under different climate change scenarios [16]. The aquifer intrinsic vulnerability models DRASTIC, SINTACS and GALDIT have been introduced in this paper as the most suitable methods to detect high contaminated areas based on the Geographical Information System (GIS). While, DRASTIC and SINTACS models have limitations for their applications to assess the vulnerability to seawater intrusion. They are not equipped to assess this kind of pollutants, as it is based on the position of pollutants on the top surface [17]. As a result of the models limitations, some researchers modified the latest to respond the critical conditions of groundwater. It is imperative to regulate future groundwater allocations and implement conservation strategies based on robust hydrogeological assessments to alleviate the adverse impacts of groundwater depletion [18]. In some researches, they modified DRASTIC method 
and added different parameters such us land use, index lineaments, aquifer thickness and impact of contaminant [19]. In this case, a comparative study for each vulnerability method maps has been added in order to find the most suitable method [20] and to build a new model "RIHM". It has been developed by coupling DRASTIC, SINTACS and GALDIT to improve understanding of seawater intrusion into the Monastir aquifer system. So, it was necessary to collect several parameter of each model from several sources and converted it into thematic maps using GIS tools. Then, it has been combined with hydrogeological data and classified based on sensitivity analysis. Furthermore, to assess groundwater vulnerability in the study area two sensitivity tests have been performed. The map removal sensitivity analysis which recognizes the sensitivity of the vulnerability map by removing one or more maps. The singleparameter sensitivity analysis was used to compare the effective or real weighting factor for each one of sensitive parameters with the theoretical weighting factor, which is allocated to the same parameter in the analytical models [21]. It helps to evaluate the effect of parameters on vulnerability indexes have carried out. The main objective of this study was to determine principal parameters determinant Monastir groundwater salinization, highlights the impact of seawater intrusion based on the groundwater vulnerability maps and the geochemical water quality and to better focus in groundwater management programs. The tool will also allow it to readily assess potential groundwater quality impacts for future changes. This study may provide environmental protection measures considered for similar regions to prevent groundwater from potential risk of pollution.

\section{Material \& Methods}

The peninsula of Monastir situated in the central eastern part of Tunisia (Figure 1 ) between $\mathrm{N} 035^{\circ}$ $47^{\prime}$ and $\mathrm{E} 010^{\circ} 50^{\prime}$. The site is contoured by the boundary of Monastir from the North and the hills of Mahdia from the south. The area spreads over approximately $1024 \mathrm{~km}^{2}$ of heterogenic landscape. Although, it exhibits some climatic variability, particularly in the distribution of rainfall regime and intensity, which varies drastically. The studied area belongs to the semi-arid to arid Mediterranean climate with drastic changes in rainfall (gradient

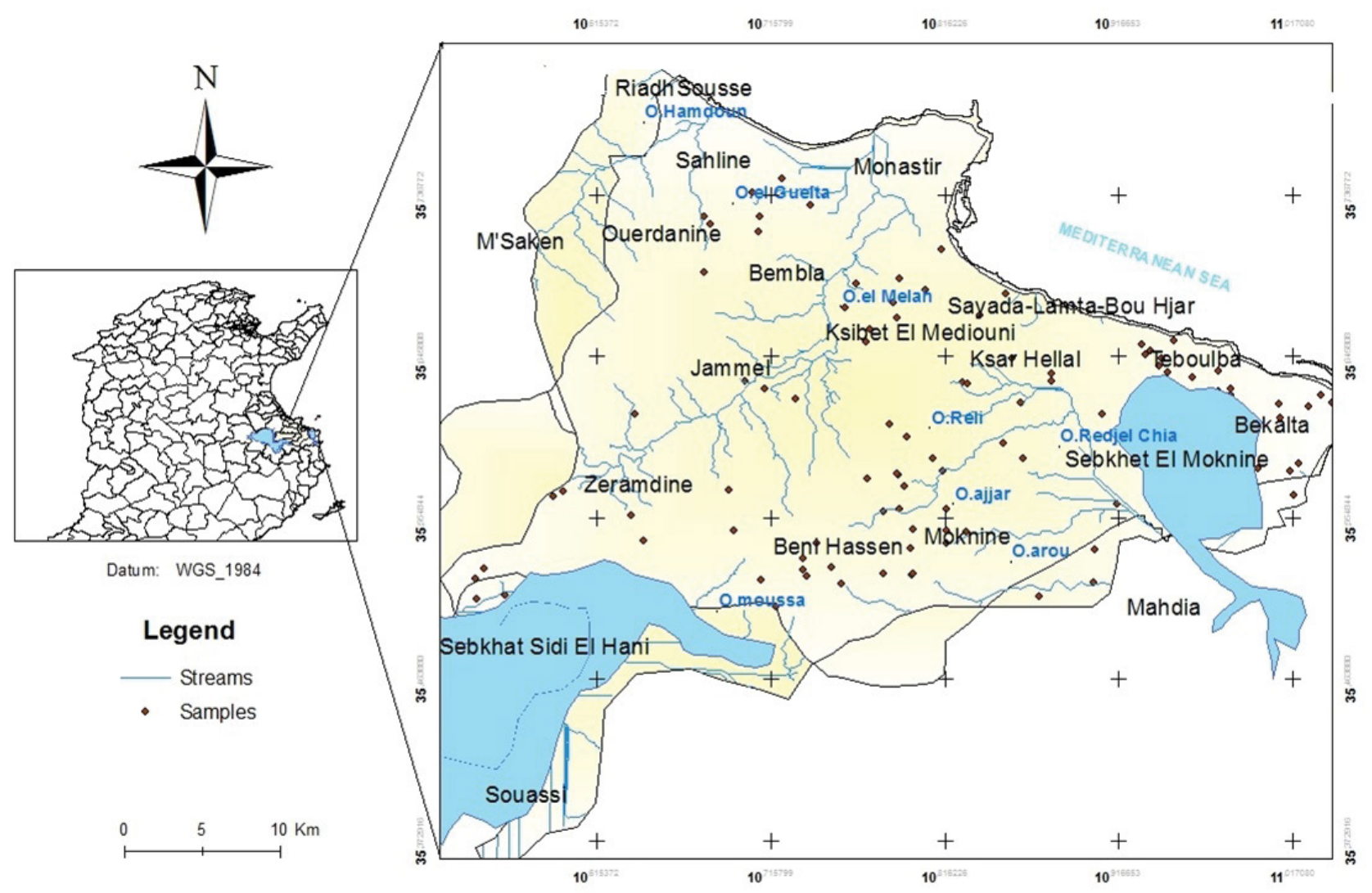

Figure 1: Geographical localization of the study area, Monastir-Tunisia. 
of approximately $342.5 \mathrm{~mm} / 1000 \mathrm{~m}$ ) [22]. These changes have a great impact on degradation of water quality and seawater intrusion. The Mediterranean Sea and Sebkhas (Sebkhat Moknine and Sidi El Hani) represent the discharge areas (Figure 1). The platform of Monastir is truncated by a fault with North-South direction, with a Cliff morphology and monotonous topography of a soft slope (0-15\%) over most of the study area. From an hydrogeological view, there isn't an important streams in Monastir. Oued El Melah is the most important in this zone (Figure 1). The aquifer system of Monastir formed by 8 shallow aquifers cited from North to south, Sahline-Ouerdanine, JammelBembla, Monastir, Ksar Hellal, Moknine, Teboulba, Bekalta, Zéramdine-béni Hassen and one deep aquifer of the Vindobonien dome of ZeramdineBeni Hassen. It is a prone area of multilayers aquifer system characterized by productive horizons aged from Upper Miocen until recent quaternary, formed by continental deposits of the Segui formation in the base (Figure 2). Subsequently, a portion of the Pliocene fields of sandy clay intercalations allowing the communication compose this aquifer system.
This lasted is gradually shifted towards by the deformed marine quaternary cliff of Monastir [23], the Tyrrhenian hills of ksibet El Mediouni and also by collapsed areas represented mainly by sebkhat Monastir [24].

\section{Data sets}

The different types of data sets used for the new model approach for vulnerability to assess seawater intrusion risk of the area under investigation were as follows:

- Geological map (Figure 1) of the study area which, display lithological units at 1:50000 scale in Geographical Coordinate System

- Topographic maps of the Regional Commission for Agricultural Development of Monastir at a scale of 1:25000 to form a detailed base map with4-m contour interval.

- Satellite sensor data and in particular, a Sentinel-2A from USGS Earth Explorer: Landsat Imagery for the coastal line of Monastir image acquired on $22^{\text {nd }}$ October 2018 with a spatial resolution of $4 \mathrm{~m}$ for the

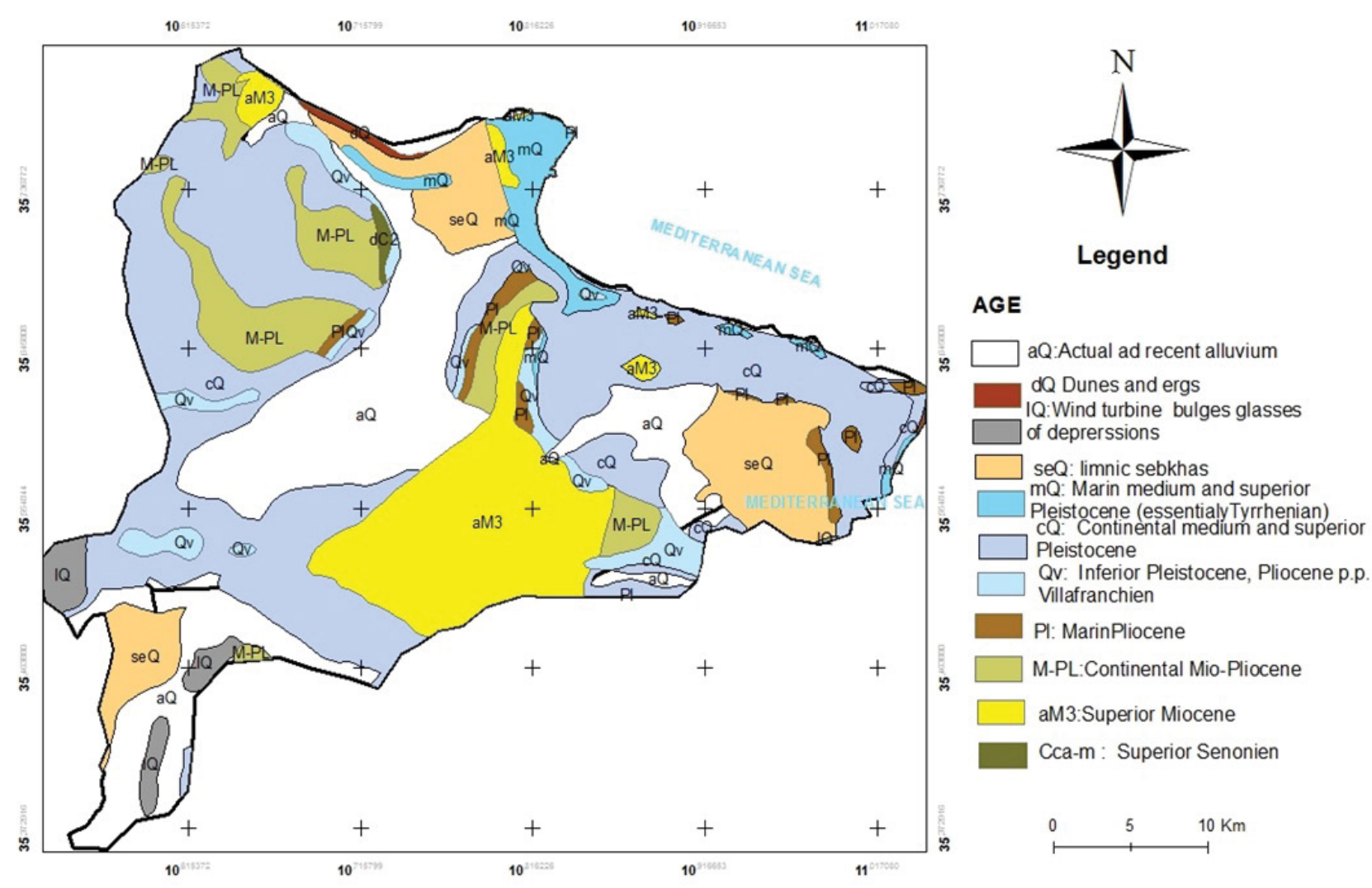

Figure 2: Edition of Digital Geologic map of Monastir aquifer system obtained from (sheet $n^{\circ} \mathrm{xx}$, in GCS_ WGS_1984, scale 1:50000, edited by ONM 1989). 
multi-spectral bands ( 4 bands) and $1 \mathrm{~m}$ for the panchromatic image.

- Field survey involving geochemistry inventory of thirty-seven samples (Laboratory analysis) have been extracted from private wells and surveillance piezometric, over all the study area (Figure 1) in October 2018. The groundwater samples results of $\mathrm{HCO}_{3}{ }^{-} \mathrm{CO}_{3}^{-2}$, $\mathrm{EC}$ and $\mathrm{Cl}^{-}$obtained from PPe laboratory of Chotrana Tunis (link site).

- Field data involving observations on published well logs and reports, Pumping Test and Piezometric analyses.

In order to create the appropriate information platform upon which to proceed in a systematic way toward applying the vulnerability models (DRASTIC, SINTACS and GALDIT) with different unique parameters characteristics for each model. Each of models indicator has been with respect to other. In fact, our aim is to determine the relatively role of each parameter in the assessment of vulnerability of contamination in order to product the final model RIHM. All available data is represented by thematic layers and used on the same GIS platform. The data processing is developed into ArcGIS Desktop 10.2 software environment. The several maps were georeferenced in the local projection system of Tunisia (Coordinate System WGS_1984). In addition, we can be able to overlay all parameters or models to compare. In the next pre-processing phase, digitization of all the relevant data maps, namely lithological, structural and topographical was carried out. The Digital Elevation Model (DEM) of the study area with resolution $(4 \mathrm{~m})$ was generated from the topographic maps of the study area. The DEM attributes allow to us to produce from further processing derived maps.

\section{The vulnerability assessment approach}

DRASTIC is an empirical model. It is developed by The US Environmental Protection Agency [25] and it is an easy method to map the vulnerability of Monastir. This method has been successfully tested in different areas of the world [26]. The DRASTIC model corresponds to seven initials parameters, used to calculate the vulnerability index value: Depth to water (D), Net Recharge (R), Aquifer media (A), Soil media (S), Topography ( $T$ ), Impact of vadose zone (I) and Hydraulic Conductivity of the aquifer (C). During the determination of the DRASTIC index (DI), each parameter is assigned a numeric rating of between 1 (least pollution potential) and 10 (highest pollution potential) depending on its value at the study area. Each parameter is also assigned by a weighting factor ranging between 1 and 5 based on their relative influence in affecting pollution potential [27]. DRASTIC classified into two weights. One is for normal conditions, has been introduced in this work and its $I V$ ranges from 23 to 230 . Other one is for intense agricultural activity conditions. Eventually, after collecting and digitizing hydrogeological information using GIS, in order to prepare vulnerability maps, all the information has been overloaded and integrated to obtain a new layer called DRASTIC index [28], Eq(1) :

$$
\begin{aligned}
& \text { DRASTIC index }=\mathrm{DI}=\sum_{\mathrm{j}=1}^{7}\{(\mathbf{W j}) \boldsymbol{R j}\} / \Sigma_{\mathrm{j}=1}^{7} \mathbf{W j} \\
& \mathbf{W j}=(D W D R+R W R R+A W A R+S W S R+T W T R+ \\
& I W I R+C W C R) / \Sigma_{j=1}^{7}\{(\mathbf{W j})\}
\end{aligned}
$$

Where $D, R, A, S, T, I$, and $C$ are the seven parameters of DRASTIC method. $R$ and $W$ are respectively, the rating and weight of each parameter.

Correspondingly to DRASTIC method, its Italian version is SINTACS. It stands from the Italian names of the parameters that are used, Soggicenza (depth to groundwater), Infiltrazione (effective infiltration), Non saturo (unsaturated zone attenuation capacity), Tipologia della copertura (soil/overburden attenuation capacity), Acquifero (saturated zone characteristics), Conducibilità (hydraulic conductivity) and Superficie topografica (topographic surface slope) [29]. In fact, it was introduced for hydrogeological, climatic and impacts settings, typical for Mediterranean countries [30]. In order to produce the final SINTACS map, all the thematic maps relating to the seven parameters were converted to raster format then overlaid, after assign in a weight to each layer based on Eq. (2) and using the spatial analyst extension of ArcGis 10.2 software in Figure 3:

$$
\begin{aligned}
& \text { SINTACS index }=S I=\sum_{j=1}^{7}\{(\mathbf{W j}) P j\} \sum_{j=1}^{7} \mathbf{W j} \\
& \mathbf{W j}=(\text { SWSP + IWIP + NWNP + TWTP + AWAP + } \\
& \text { CWCP }+ \text { SWSP }) / \Sigma_{j=1}^{7}\{(\mathbf{W j})\}
\end{aligned}
$$

Where $\mathrm{SI}$ is the vulnerability index based on SINTACS model. $\mathrm{Pj}$ and $\mathrm{Wj}$ are ratings and weights respectively of the grid cell. S: Slope, C: Conductivity, A: Hydrogeological aquifer characteristics, T: Soil type, N: Vadose zone, I: Net recharge and S: Depth to water. 

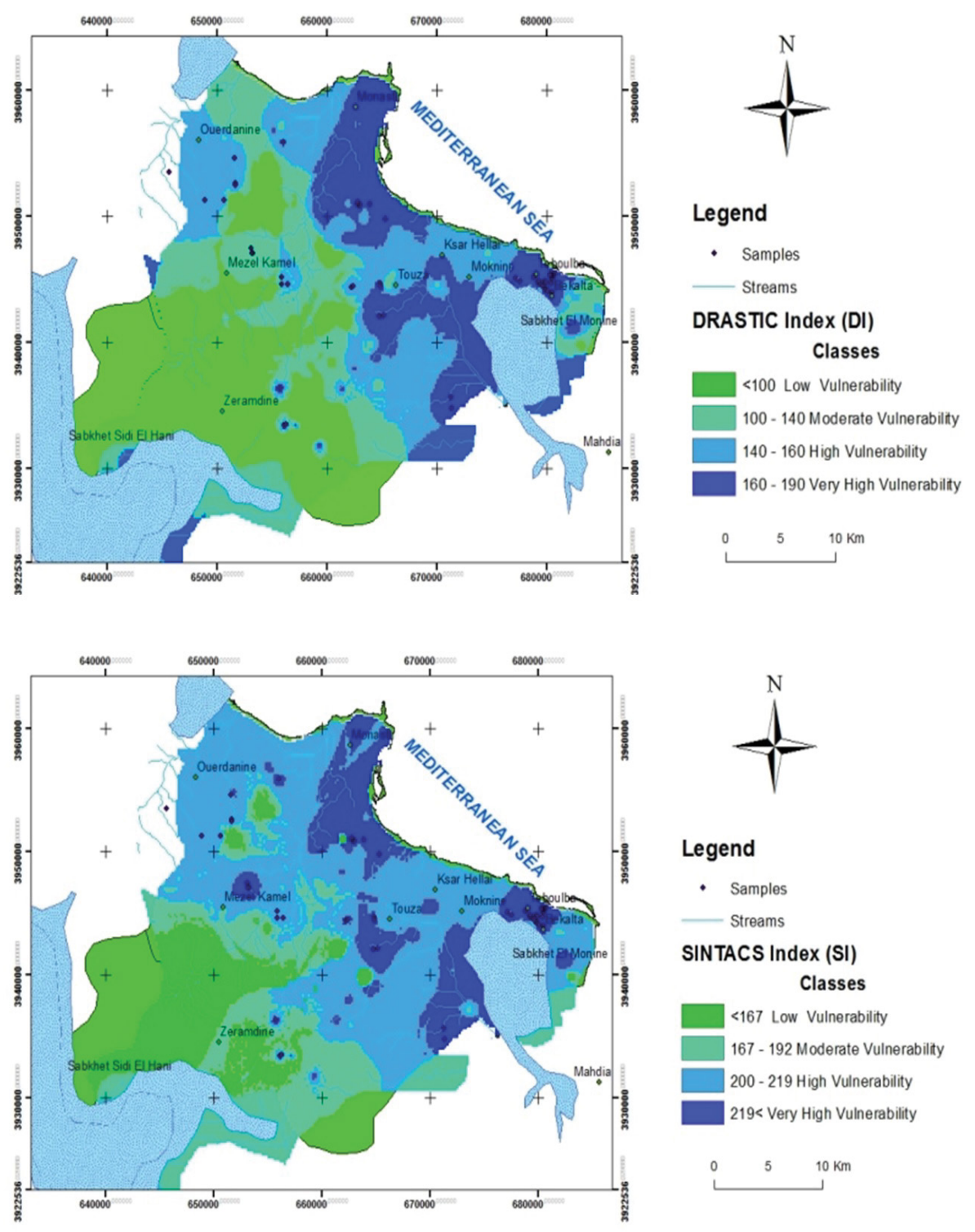

\section{Legend}

- Samples

$$
\text { - Streams }
$$

SINTACS Index (SI)
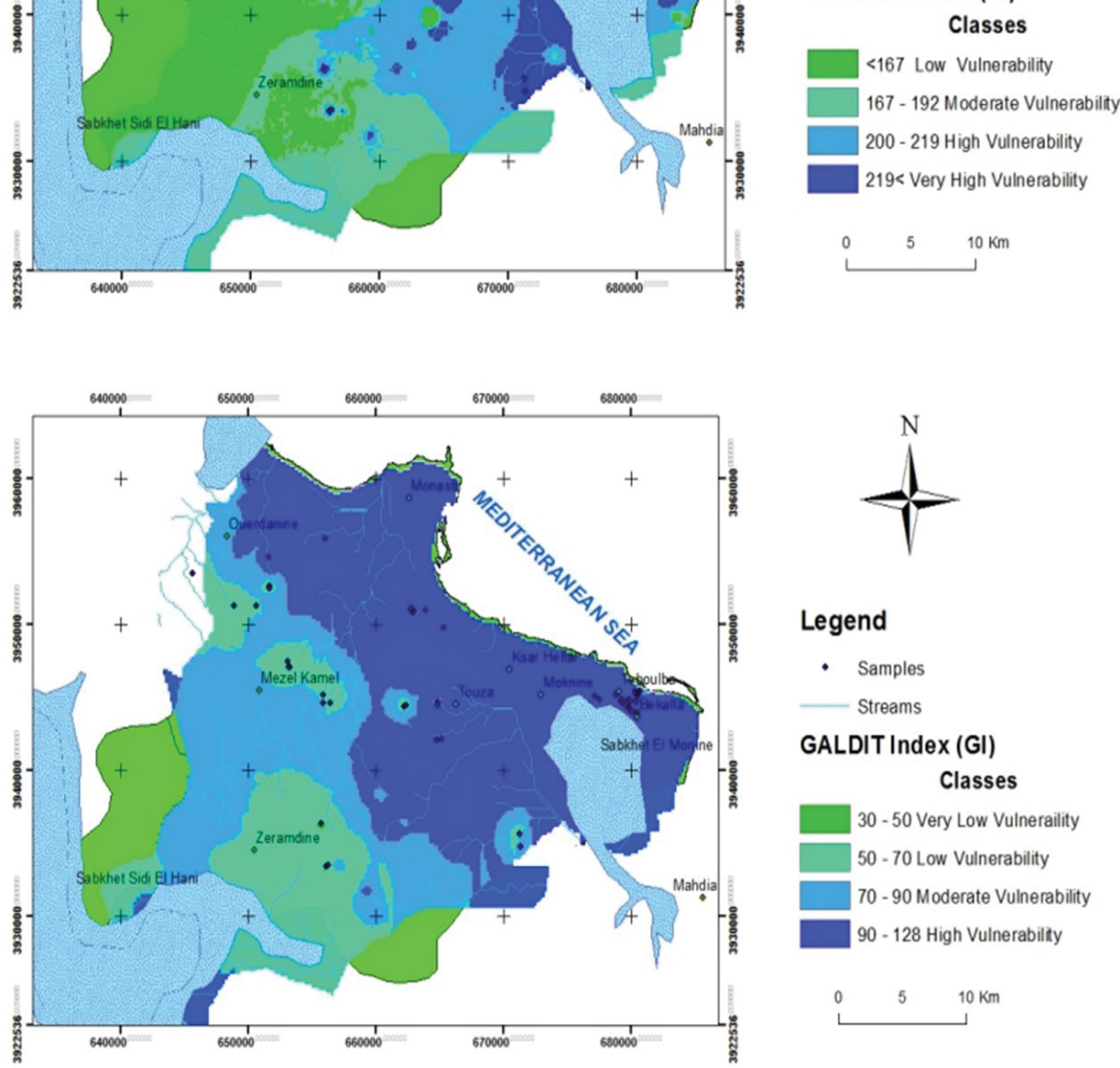

\section{Legend}

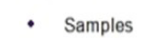

Streams

GALDITIndex (GI)

\section{Classes}

$30-50$ Very Low Vulneraility

$50-70$ Low Vulnerability

70 - 90 Moderate Vulnerability

$90-128$ High Vulnerabilty

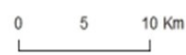

Figure 3: The vulnerability indexes ( $/ v$ ) maps for DRASTIC, SINTACS and GALDIT methods (Coordinate System NTT: Defined by UTM projection system and Clarke 1980, as the local Geodetic reference frame of Tunisia). 
GALDIT method was essentially an idea It commonly used physical characteristics affected developed from DRASTIC method. But it has the groundwater pollution potential [31], to assess different hydrogeological parameters which vulnerability depth in extended regions [32]. Its influences the seawater intrusion in the aquifer. parameters are: Groundwater occurrence (aquifer

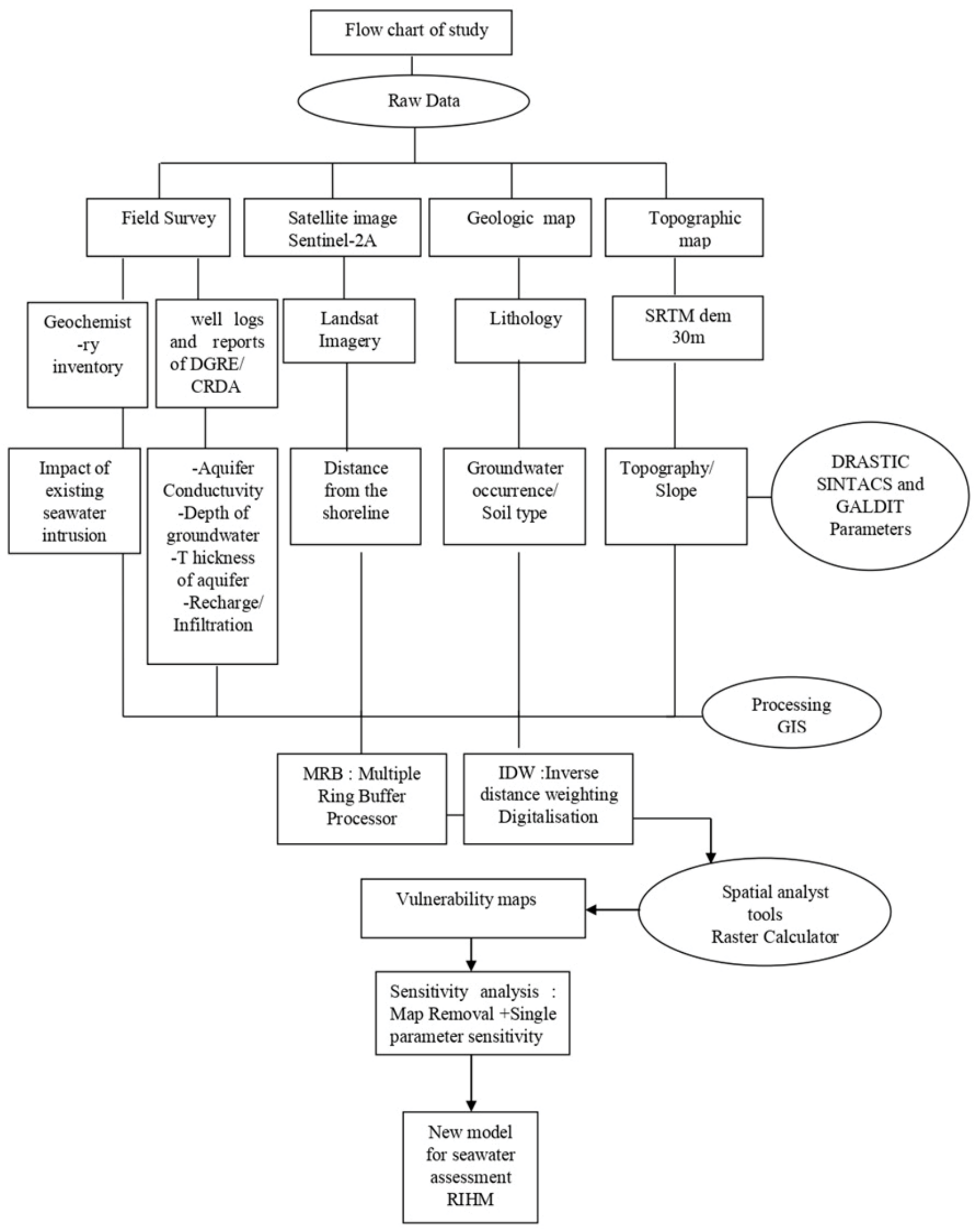

Figure 4: Methodological flowchart of the vulnerability assessment approach followed in this study. 
type), Aquifer hydraulic conductivity, Depth to groundwater level above the sea, Distance from the shore (distance inland perpendicular from shoreline), Impact of existing status of seawater intrusion in the area and Thickness of the aquifer [8]. In short, GALDIT is a numerical ranking system to assess groundwater pollution potential in hydrogeological setting. It assigns a note between 1 and 10 and a weight between 1 and 5 for each used parameter [33], Eq. (3):

$$
\begin{aligned}
& \text { GALDIT index }=\mathrm{GI}=\sum_{\mathrm{i}=1}^{6}\{(\mathbf{W i}) \boldsymbol{R i}\} / \Sigma_{\mathrm{i}=1}^{6} \mathbf{W i} \\
& \mathbf{W i}=(\mathbf{G W G R}+\boldsymbol{A W A R}+L \mathrm{WLR}+\boldsymbol{D W D R}+\boldsymbol{W} I \mathrm{R}+ \\
& \text { TWTR }) / \Sigma_{\mathrm{i}=1}^{6}\{(\mathbf{W i})\}
\end{aligned}
$$$$
\mathrm{GI}=(1 \cdot G \mathrm{R}+3 \cdot A \mathrm{R}+4 \cdot \mathrm{LR}+4 \cdot D \mathrm{R}+1 \cdot \mathrm{IR}+2 \cdot \mathrm{TR}) / 15
$$

Where $\boldsymbol{W} \boldsymbol{i}$ is the weight of the $\boldsymbol{i}^{\boldsymbol{t h}}$ indicator and $\boldsymbol{R} \boldsymbol{i}$ is the importance rating of the $\boldsymbol{i}^{\text {th }}$ indicator.

\section{Sensitivity analysis}

In order to assess groundwater vulnerability in the study area two sensitivity tests have been performed. In one hand, the map removal sensitivity analysis which recognizes the sensitivity of the vulnerability map by removing one or more maps and can be determined using the following Eq.4:

$$
S=\left(\left|V / N-V^{\prime} / n\right| / V\right) * 100
$$

With S: The sensitivity measure, $\mathrm{V}$ : Unperturbed vulnerability index (obtained using all seven parameters), V': Perturbed one (using a smaller number of data layers), $\mathrm{N}$ and $\mathrm{n}$ : The data layers number which is used to calculate $V$ and $V^{\prime}$.

In the other hand, Napolitano and Fabri to evaluate the effect of parameters on vulnerability indexes have carried out the single-parameter sensitivity analysis. This method was used to compare the effective or real weighting factor for each one of sensitive parameters with the theoretical weighting factor, which is allocated to the same parameter in the analytical models [21]. DRASTIC, SINTACS and GALDIT effective weighting factors were computed using the following Eq.5:

$$
W=\left(P_{r} P_{w} / V\right) * 100
$$

With $W$ is the "effective" weight for each factor, $\mathrm{Pr}$ and $\mathrm{PW}$ are the rating value and weight for each parameter, $V$ is the vulnerability index. ArcGIS software has been used to compute all combinations of parameters and weights in the study area and have been considered in the statistical analysis of the results [34] (Figure 4).

\section{Results and Discussion}

\section{Intrinsic methods}

The vulnerability indexes $(I v)$ for all models have been calculated to subdivide the final vulnerability maps into classes from low to high or very high vulnerability indexes. The comparison between DRASTIC, SINTACS and GALDIT vulnerability indexes, which are respectively 100-190, 167-219 and $30-128$ shows the similarity distribution of each vulnerability index. High vulnerability indexes are principally for the coastal area. In GALDIT vulnerability map, a huge enlargement of seawater intrusion could be visualized in more than $2 \mathrm{~km}$ inland (Figure 3). Therefore, the important quantity of water and the great-saturated zones reserved in little depths like north and southwest parts of the study area dominated by low vulnerability classes. They assigned to the lower rating value of about one to three for depths between 84.47 to $8 \mathrm{~m}$ (Figure 5). In addition to that, the lower depths can protect groundwater resources from seawater contamination but has to be in a leaky confined aquifer with lower permeability. The leaky confined aquifers found here are with lower vulnerability conditions due to the subsequent replenishment of fresh water by infiltration from the hydrographical interaction. However, confined aquifers could be vulnerable to seawater intrusion when there is a large cone of depression created due to overexploitation [35]. Stressful values of $I v$ induced to thick Plio-Quaternary series as consequence of previous tectonic activities in multiple phases of distension and compression in the Sahel area [36].

The tectonic distension during the Serravalien Tortonian and Messinian as well as the compression of late Tortonien controlled the fluvio deltaic Miocene sediment. The major tectonics structures are Northern border of Zéramdine platform composed of NW-SE and WNW-ESE faults. Moknine faults divided Miocene series into Jemmal platform NW and Zéramdine SE $([37,38])$. The littoral plains of Jemmal take place within collapsed zone with a syncline character or a graben form. This explains the fact that, the topographic surfaces provide the greatest opportunity for the salt water intrusion [39]. Moreover, sandy and clayey sandy reservoirs of the aquifer (Figure 6) in small slopes resulted of persistent anticlines fractured handled to higher permeability and thus handled huge pollution potential of the aquifer. So, significant vulnerability 


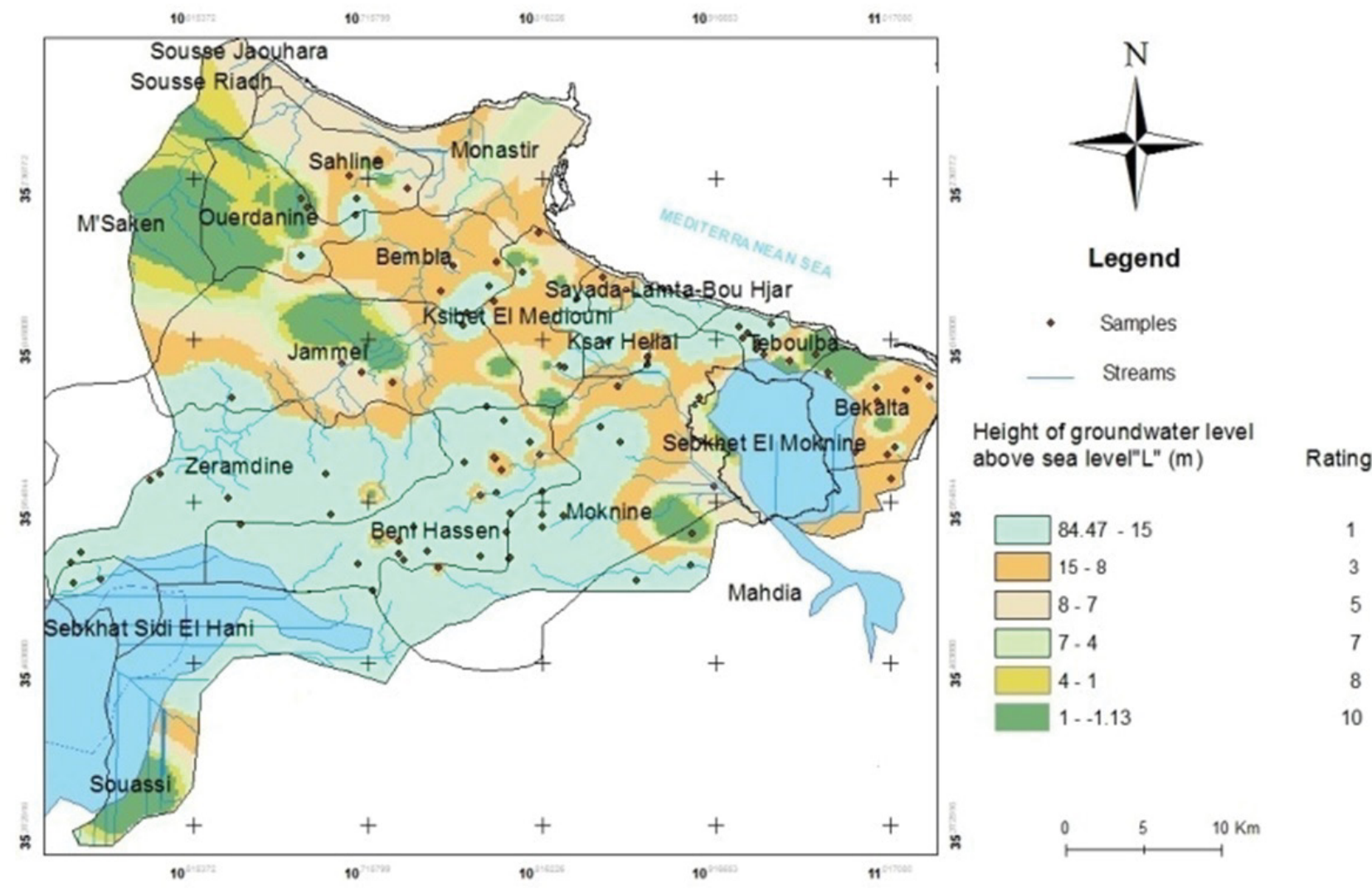

Figure 5: Height of groundwater level above sea level (L) for GALDIT model for Monastir aquifer system.

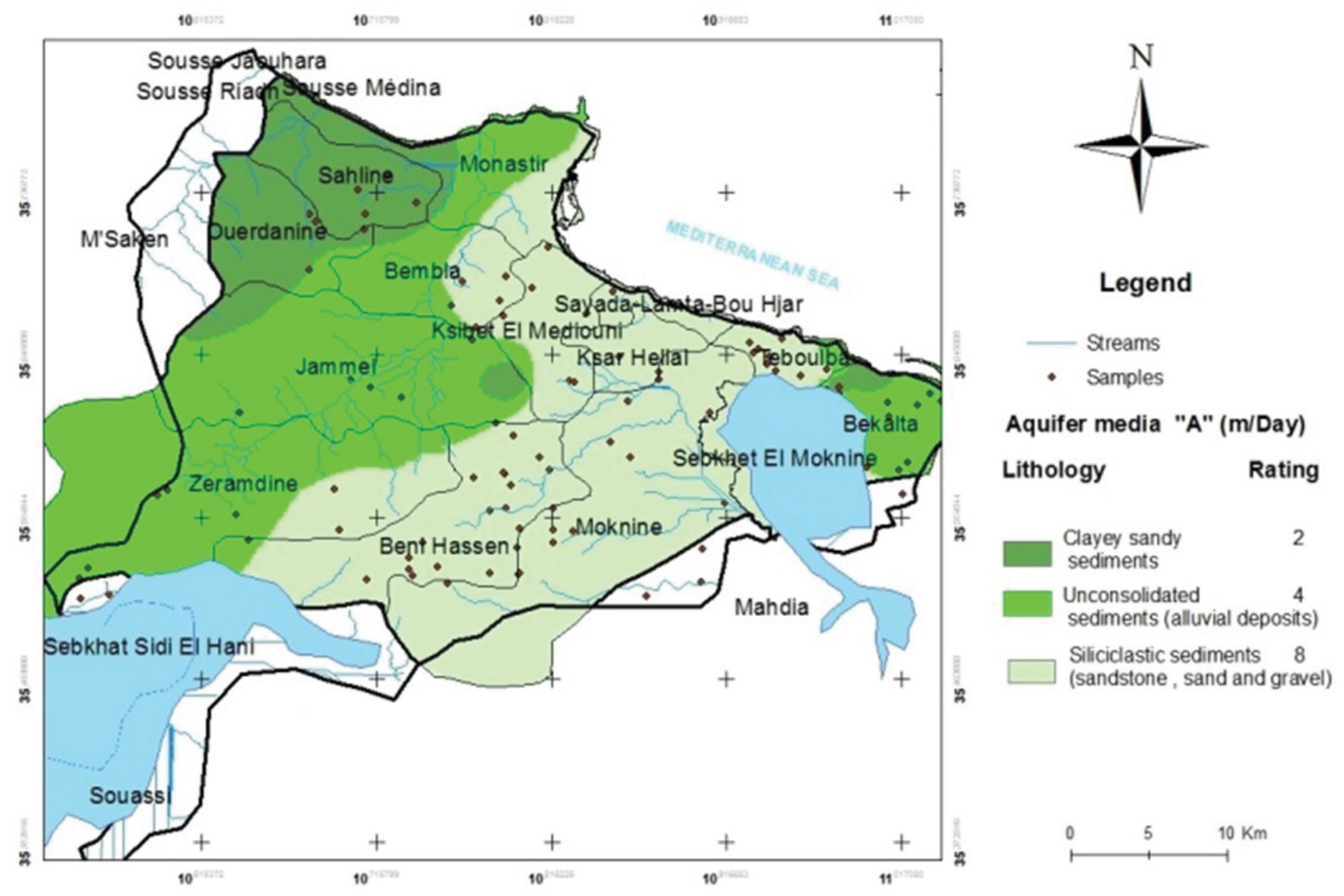

Figure 6: Aquifer media (A) for DRASTIC model for Monastir aquifer system. 

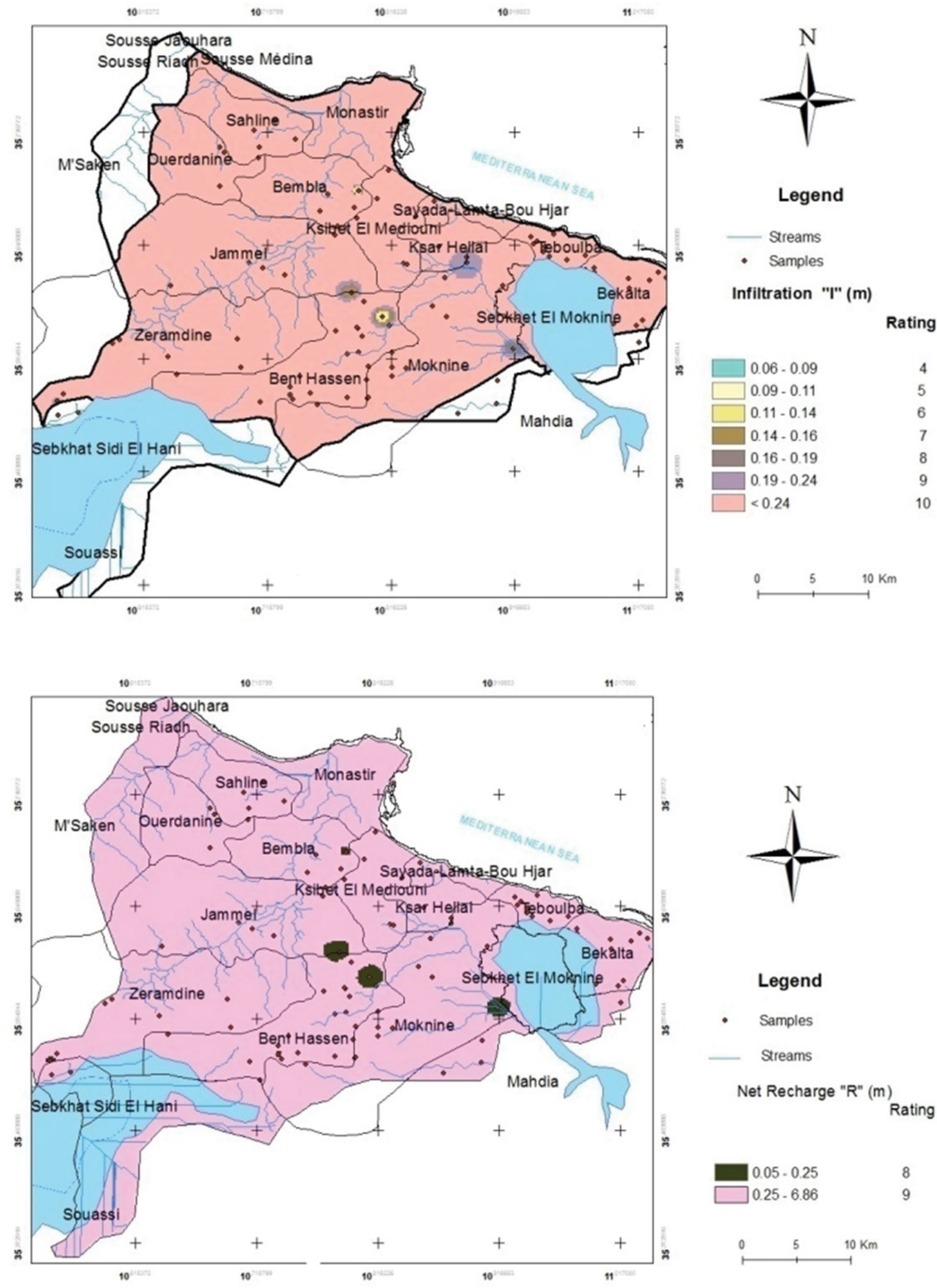

Figure 7: Infiltration (I) for SINTACS (a) and Net recharge (R) for DRASTIC (b) models for Monastir aquifer system. 
may be caused by a gentle slope and shallow depth of groundwater for the sandy aquifer. It has important permeability and transport quickly pollutants into the aquifer. This lithology increases automatically the degree of contaminant transport in the aquifer due to its high infiltration rate.

In general high vulnerability is high net recharge (Figure 7) and well correlated with the slope of the region. Except, with assessment of seawater intrusion high important net recharge defense the broking of the interface. The lowest $I v$ is usually accompanied with low hydraulic conductivity rate between 0.034 to $10 \mathrm{~m} /$ day (Figure 8). The northwestern, central-eastern, and few parts of the coastal near shore area have the greatest hydraulic conductivities ( $60 \mathrm{~m} / \mathrm{day}$ ). It is distributed to high $I v$. Because of clay-dominated soil type of Pliocene compact sediments in central part are even lower than that of Pleistocene sediments. Therefore, these areas have been assigned with a rating value of five due to its low vulnerability towards aquifer. To resume, very high vulnerability drawn in the vulnerability maps, characterized unconfined aquifer without any protecting layer, highly fractured with depth $<50 \mathrm{~m}$. Furthermore, for moderate vulnerability is characterized by depth to groundwater $>50 \mathrm{~m}$ with a medium to fine grained sand aquifer. Low vulnerability could be saved in an in-fissured sandstone or/and noncarbone cemented conglomerate aquifer. Very low or null vulnerability practically described

Table 1: Statistics of the one-map removal sensitivity analysis of DRASTIC for the Monastir aquifer system.

\begin{tabular}{|c|c|c|c|c|c|c|c|c|}
\hline \multicolumn{2}{|c|}{ Parameter removed } & D & $\mathbf{R}$ & A & $\mathbf{S}$ & $\mathbf{T}$ & $\mathbf{I}$ & C \\
\hline \multirow{4}{*}{ 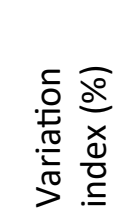 } & Minimum & 1.4 & 1 & 0.7 & 1 & 1 & 1.4 & 1.7 \\
\hline & Maximum & 2.2 & 1.75 & 2.33 & 2.5 & 2 & 2 & 2.33 \\
\hline & Mean & 1.5 & 1.43 & 1.73 & 1.7 & 1.3 & 1.68 & 2.13 \\
\hline & $\mathrm{CV}^{*}$ & 11.86 & 8.84 & 5.45 & 16.33 & 14.35 & 8.47 & 6.26 \\
\hline
\end{tabular}

${ }^{*} \mathrm{CV}$ : Coefficient of Variation.

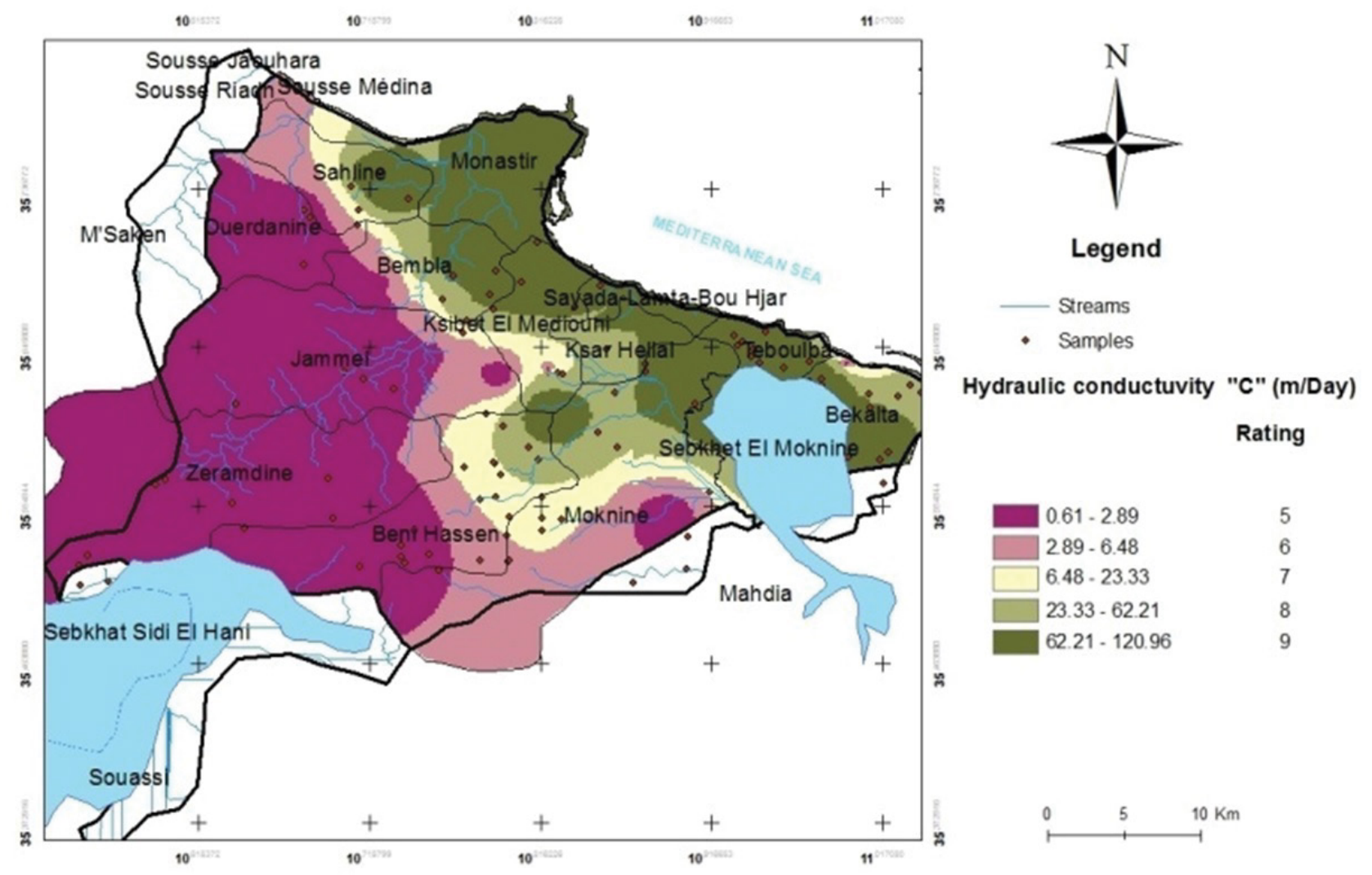

Figure 8: Hydraulic conductivity (C) for SINTACS model for Monastir aquifer system. 
the impermeable aquifer formed by marl and clay sedimentary complexes with fine-grained sedimentary complexes.

\section{Supplementary materials}

\section{${ }^{*}$ Map removal sensitivity analysis}

Table 1 illustrates the variation of vulnerability index as a result of removing only one DRASTIC parameter at a time. The results reveal that the most sensitive parameter is the hydraulic conductivity, C (mean variation index: 2.13\%). Furthermore, the vulnerability index seems to be sensitive to the removal of the aquifer media (A) as the mean variation index is $1.73 \%$, although the low real weight $(8.69 \%)$ (Table 2 ) relative to removing the soil texture $(\mathrm{S})$ caused a variation of $1.7 \%$. The least sensitive parameter is the topography, $\mathrm{T}(1.3 \%)$, view its low "theoretical" weight (2) assigned to it. To resume, the sequence of variation index is $C>A>S>I>D>R>T$, which is quite different from the order of their magnitudes of the theoretical weight, i.e., $D=I>R>A=C>$ $\mathrm{S}>\mathrm{T}$. The results of the map removal sensitivity indicate that the removal of each parameter will influence groundwater vulnerability and it is really necessary to use all of the seven parameters to assess groundwater vulnerability in the Monastir aquifer. Additionally, Table 3 demonstrates the variation of the vulnerability index due to the removal of one or more data layers at a time from the DRASTIC model computation. The layers which cause less variation of the vulnerability index were removed one-by-one, to leave just one with the most important theoretical weight. The highest variation is associated with the removal of Aquifer media $(A)$ and the soil texture $(T)$ parameters and the least variation is observed after removing the impact of the vadose zone parameter, I. The variation index increased as the number of layers excluded from the DRASTIC computation increased. Through this sensitivity analysis, it is clear that a considerable variation in the vulnerability assessment is expected if a few parameters have been integrated. Furthermore, this kind shows that as the map removal sensitivity of one parameter, all the parameters are necessary to work out the vulnerability index.

Table 4 illustrates the variation of vulnerability index as a result of removing a layer from SINTACS. It is clear that high variation of vulnerability index is expected on the removal of aquifer media, A (mean variation index: $2.03 \%$ ). This can be attributed to the important "theoretical" weight assigned to this layer (3). Furthermore, vulnerability index seems to be sensitive to the removal of the texture of soil ( $T$ ) as the mean variation index is $1.97 \%$, in spite the high real weight (19.23\%) (Table 5), relative to removing the non-saturated impact $(\mathrm{N})$. It caused a variation of about $1.86 \%$. The least sensitive parameter is topography, S $(1.47 \%)$, with low "theoretical" weight (2). Table 2 demonstrates the variation of vulnerability index due to the removal of one or more data layers at a time from SINTACS. Layers attributed the least variation of vulnerability

Table 2: Statistics of map removal sensitivity analysis of SINTACS for the Monastir aquifer system.

\begin{tabular}{|c|c|c|c|c|c|c|c|}
\hline \multicolumn{2}{|c|}{ Parameter used } & \multirow{2}{*}{$\begin{array}{l}\text { SINTAC } \\
3\end{array}$} & \multirow{2}{*}{$\begin{array}{l}\text { SINTC } \\
9\end{array}$} & \multirow{2}{*}{\begin{tabular}{|l} 
SINT \\
13 \\
\end{tabular}} & \multirow{2}{*}{\begin{tabular}{|l} 
SIN \\
20
\end{tabular}} & \multirow{2}{*}{\begin{tabular}{|l|} 
SN \\
25
\end{tabular}} & \multirow{2}{*}{\begin{tabular}{|l|}
$\mathbf{N}$ \\
34 \\
\end{tabular}} \\
\hline \multirow{4}{*}{ 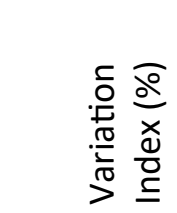 } & Minimum & & & & & & \\
\hline & Maximum & 7 & 13 & 18 & 24 & 30 & 37 \\
\hline & Mean & 4.4 & 10.4 & 15.6 & 21.5 & 27.5 & 35.6 \\
\hline & $\mathrm{CV}^{*}$ & 13.07 & 6.68 & 4.54 & 3.39 & 3.26 & 2.4 \\
\hline
\end{tabular}

${ }^{*} \mathrm{CV}$ : Coefficient of Variation.

Table 3: Statistics of map removal sensitivity analysis of DRASTIC for the Monastir aquifer system.

\begin{tabular}{|c|c|c|c|c|c|c|c|}
\hline \multicolumn{2}{|c|}{ Parameter removed } & DRASIC & DRAIC & DRIC & DRI & DI & I \\
\hline \multirow{4}{*}{ 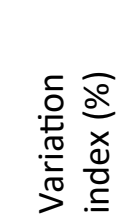 } & Minimum & 1 & 2 & 5 & 12 & 16 & 26 \\
\hline & Maximum & 2 & 7 & 14 & 20 & 26 & 33 \\
\hline & Mean & 1.3 & 4.7 & 9.9 & 16.3 & 22 & 30 \\
\hline & $\mathrm{CV}^{*}$ & 14.35 & 13.12 & 14.64 & 9.12 & 7.12 & 5.11 \\
\hline
\end{tabular}

${ }^{*} \mathrm{CV}$ : Coefficient of Variation. 
Table 4: Statistics of the one-map removal sensitivity analysis of SINTACS for the Monastir aquifer system.

\begin{tabular}{|c|c|c|c|c|c|c|c|c|}
\hline \multicolumn{2}{|c|}{ Parameter removed } & $\mathbf{S}$ & I & $\mathbf{N}$ & $\mathbf{T}$ & A & C & $\mathbf{S}$ \\
\hline \multirow{4}{*}{ 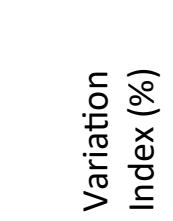 } & Minimum & 1.4 & 1.3 & 1.6 & 1.3 & 1.3 & 1.3 & 1 \\
\hline & Maximum & 2.2 & 1.8 & 2.2 & 2 & 2.3 & 2 & 2.3 \\
\hline & Mean & 1.61 & 1.48 & 1.86 & 1.97 & 2.03 & 1.7 & 1.47 \\
\hline & $\mathrm{CV}^{*}$ & 8.43 & 6.89 & 8.23 & 8.42 & 10.02 & 4.74 & 13.07 \\
\hline
\end{tabular}

${ }^{*} \mathrm{CV}$ : Coefficient of Variation.

Table 5: Statistics of single parameter sensitivity analysis of SINTACS for the Monastir aquifer system.

\begin{tabular}{|c|c|c|c|c|c|c|}
\hline \multirow[t]{2}{*}{ Parameter } & \multirow{2}{*}{$\begin{array}{l}\text { Theoretical } \\
\text { weight }\end{array}$} & \multirow{2}{*}{$\begin{array}{l}\text { Relative } \\
\text { theoretical } \\
\text { weight \% }\end{array}$} & \multicolumn{4}{|c|}{ Effective weight\% } \\
\hline & & & Minimum & Maximum & Mean & $\mathrm{CV}^{*}$ \\
\hline$S$ & 5 & 19.23 & 7 & 31 & 23.25 & 17.47 \\
\hline I & 4 & 15.38 & 15 & 29 & 21.17 & 11.71 \\
\hline $\mathrm{N}$ & 5 & 19.23 & 8 & 25 & 15.66 & 29.30 \\
\hline $\mathrm{T}$ & 4 & 15.38 & 4 & 17 & 7.01 & 43.04 \\
\hline$A$ & 3 & 11.54 & 3 & 17 & 6.43 & 56.71 \\
\hline C & 3 & 11.54 & 8 & 19 & 12.20 & 19.81 \\
\hline S & 2 & 7.69 & 2 & 26 & 16.61 & 20.65 \\
\hline
\end{tabular}

${ }^{*} \mathrm{CV}$ : Coefficient of Variation.

Table 6: Statistics of the one-map removal sensitivity analysis of GALDIT for the Monastir aquifer system.

\begin{tabular}{|c|c|c|c|c|c|c|c|}
\hline \multicolumn{2}{|c|}{ Parameter removed } & G & A & $\mathbf{L}$ & D & I & $\mathbf{T}$ \\
\hline \multirow{4}{*}{ 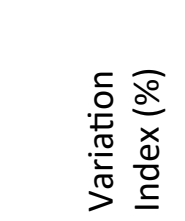 } & Minimum & 0 & 0.7 & 0.3 & 1 & 0 & 1 \\
\hline & Maximum & 2 & 3 & 3 & 3 & 2 & 2.5 \\
\hline & Mean & 1.35 & 1.81 & 1.61 & 2.32 & 1.5 & 1.99 \\
\hline & $\mathrm{CV}^{*}$ & 36.52 & 28.91 & 25.49 & 13.75 & 30.85 & 14.23 \\
\hline
\end{tabular}

${ }^{*} \mathrm{CV}$ : Coefficient of Variation.

index were removed one-by-one, to leave just one with the most important theoretical weight. The highest variation is associated with the removal of topography $(\mathrm{S})$ and texture of soil $(\mathrm{T})$ parameters. The least variation is observed after removing depth of groundwater (S).

Table 6 illustrates the variation of the vulnerability index for GALDIT by removing a layer at a time. It is clear that high variation of vulnerability index is expected on removal of distance from the shoreline, D (mean variation index: $2.32 \%$ ). While it has low, "theoretical" weight assigned to this layer (2) but this kind of pollution "seawater intrusion "depends essentially of its approximity to coastline. The vulnerability index seems to be sensitive to the removal of aquifer thickness $(T)$ as the mean variation index is $1.99 \%$, with the most important theoretical weight $(23.08 \%)$ (Table 7 ), relative to removing the hydraulic conductivity $(A)$ caused a variation of $1.81 \%$. The least sensitive parameter is groundwater occurrence $\mathrm{G}(1.35 \%)$, view its low "theoretical" weight (1) assigned to it, and impact of the existing status of seawater intrusion (I), based on the $\mathrm{SO}_{4}{ }^{2-} / \mathrm{Cl}^{-}$ratio with (1.50\%). This is due to the decreasing pressure of seawater comparing to freshwater because of the dominance of unconfined aquifer in the study area, and thus a direct connection between these parameters and pollution control.Table 8 demonstrates the variation of the vulnerability index due to the removal of one or more data layers at a time from GALDIT model computation. The layers with less variation influence for vulnerability index were removed 
Table 7: Statistics of single parameter sensitivity analysis of GALDIT for the Monastir aquifer system.

\begin{tabular}{|c|c|c|c|c|c|c|}
\hline \multirow{2}{*}{ Parameter } & \multirow{2}{*}{$\begin{array}{l}\text { Theoretical } \\
\text { weight }\end{array}$} & \multirow{2}{*}{$\begin{array}{l}\text { Relative } \\
\text { theoretical } \\
\text { weight \% }\end{array}$} & \multicolumn{4}{|c|}{ Effective weight \% } \\
\hline & & & Minimum & Maximum & Mean & $S^{*}$ \\
\hline G & 1 & 7.69 & 6 & 29 & 10.33 & 3.43 \\
\hline A & 3 & 23.08 & 4 & 38 & 22.85 & 7.85 \\
\hline $\mathrm{L}$ & 4 & 30.77 & 7 & 60 & 33.87 & 8.36 \\
\hline D & 2 & 15.38 & 3 & 24 & 10.14 & 3.19 \\
\hline I & 1 & 7.69 & 6 & 28 & 9.36 & 2.87 \\
\hline $\mathrm{T}$ & 2 & 15.38 & 7 & 22 & 13.46 & 2.83 \\
\hline
\end{tabular}

*SD: Standard Deviation.

Table 8: Statistics of map removal sensitivity analysis of GALDIT for the Monastir aquifer system.

\begin{tabular}{|c|c|c|c|c|c|c|}
\hline \multicolumn{2}{|c|}{ Parameter used } & \multirow{2}{*}{$\begin{array}{l}\text { GALDT } \\
0\end{array}$} & \multirow{2}{*}{$\begin{array}{l}\text { ALDT } \\
0\end{array}$} & \multirow{2}{*}{$\begin{array}{l}\text { ALT } \\
1\end{array}$} & \multirow{2}{*}{$\begin{array}{l}\text { AL } \\
8\end{array}$} & \multirow{2}{*}{$\begin{array}{l}\mathbf{L} \\
11\end{array}$} \\
\hline \multirow{4}{*}{ 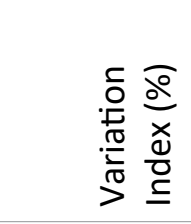 } & Minimum & & & & & \\
\hline & Maximum & 2 & 4 & 7 & 13 & 22 \\
\hline & Mean & 1.5 & 2.85 & 7.49 & 11.47 & 16.89 \\
\hline & $\mathrm{CV}^{*}$ & 30.85 & 31.09 & 11.53 & 7.2 & 9.55 \\
\hline
\end{tabular}

${ }^{*} \mathrm{CV}$ : Coefficient of Variation.

Table 9: Statistics of single parameter sensitivity analysis of DRASTIC for the Monastir aquifer system.

\begin{tabular}{|c|c|c|c|c|c|c|}
\hline \multirow{2}{*}{ Parameter } & \multirow{2}{*}{$\begin{array}{l}\text { Theoretical } \\
\text { weight }\end{array}$} & \multirow{2}{*}{$\begin{array}{l}\text { Relative } \\
\text { theoretical } \\
\text { weight \% }\end{array}$} & \multicolumn{4}{|c|}{ Effective weight \% } \\
\hline & & & Minimum & Maximum & Mean & $\mathrm{CV}^{*}$ \\
\hline D & 5 & 21.74 & 7 & 38 & 26 & 20.18 \\
\hline$R$ & 4 & 17.39 & 17 & 32 & 23 & 13.31 \\
\hline A & 3 & 13.04 & 4 & 18 & 11 & 38.98 \\
\hline$S$ & 2 & 8.69 & 1 & 19 & 8 & 42.67 \\
\hline $\mathrm{T}$ & 1 & 4.35 & 1 & 10 & 7 & 16.73 \\
\hline 1 & 5 & 21.74 & 11 & 31 & 21 & 20.2 \\
\hline$C$ & 3 & 17.39 & 2 & 10 & 5 & 53.26 \\
\hline
\end{tabular}

${ }^{*} \mathrm{CV}$ : Coefficient of Variation.

one-by-one to leave just the one with the most important theoretical weight. The highest variation is associated with the removal of aquifer media $(A)$ parameter and the least variation is observed after removing both distance from the shoreline (D) and thickness of aquifer $(T)$ parameters. The variation index increased as number of layers excluded from GALDIT computation increased. Through this sensitivity analysis, it is clear that a considerable variation in vulnerability assessment is expected if a few parameters have been integrated.

\section{*Single-parameter sensitivity analysis}

Table 5, Table 7 and Table 9 illustrate statistics of single parameter sensitivity analysis for DRASTIC, SINTACS and GALDIT for Monastir aquifer system. The "effective" weight is a function of other parameters as well as the weight assigned to it by each model. The "effective" weights of DRASTIC, SINTACS and GALDIT parameters exhibited some deviation from the "theoretical" weight. The net recharge (R) of DRASTIC tends to be the effective parameter in the vulnerability assessment with an average weight of $23 \%$ against the "theoretical" weight (17.4\%). The "effective" weight of the infiltration (I) of SINTACS (21.17\%) greatly exceeds 
the "theoretical" weight assigned by DRASTIC $(15.38 \%)$. Similarly, the calculated weights of the hydraulic conductivity of GALDIT (A) and the distance from the shoreline (D) $(41.78 \%$ and $41.66 \%$, respectively). They exceed "theoretical" weights $(23.08 \%$ and $15.38 \%$, respectively). The significance of hydraulic conductivity, net recharge and depth to water layers highlight the importance of obtaining accurate, detailed, and representative information about these factors.

\section{New model index: RIHM}

To propose some management scenarios and projecting aquifer responses for various changes, it has been concluded from DRASTIC, SINTACS and GALDIT indexes a new index model "RIHM" in order to evaluate potential risk. The determination of this new model is based on the intrinsic characteristics of the aquifer and the presence of potentially polluting activities and conditions that can be the main source of seawater intrusion for Monastir aquifer system. Combination of aquifer vulnerability results and geochemical data could be suitable for the assessment of seawater intrusion. Therefore, RIHM has highly idealized parameters, concluded from sensitivity analysis of the three vulnerability methods. The capability of the new model, to reliably project aquifer responses, is also related to the accuracy of the input data used in the vulnerability mapping and stresses related to socioeconomic development, which affect the study area [40]. RIHM is an overlay and index method which corresponds to four initials parameters concluded to calculate the vulnerability index value:

- Recharge (R): It has been obtained by raster calculator. It is the sum of DRASTIC net recharge parameter and SINTACS infiltration parameter (Figure 7). Its weighting factor is 4.

- Impact of seawater intrusion (I): The GALDIT parameter, $\left[\mathrm{Cl}^{-}\right] /\left[\mathrm{HCO}_{3} ; \mathrm{CO}_{3}{ }^{2-}\right]$, which is referred to the Revelle coefficient, has been used to evaluate the magnitude of contamination by seawater intrusion in coastal aquifers. The impact of seawater intrusion decreases when moving perpendicularly from shore towards the land. The further away the groundwater is from shore the lesser the pressure of seawater to infiltrate into the aquifer [17]. The ratio of these two ions is used to assign a rating value for the new parameter (I). It has been assigned a weighting factor 1 .

- Hydraulic conductivity of aquifer $(\mathrm{H})$ : The hydraulic conductivity of SINTACS parameter (Figure 8) has been reclassified to get the new parameter. It has a weighting factor 3.

- Mixed-up of saturated and unsaturated aquifer zones: It is concluded with raster calculator and it is the sum of the DRASTIC impact of saturated zone parameter (aquifer media) (Figure 6) and the SINTACS non-saturated zone media. It has been assigned a weighting factor 5 , view the importance of this factor in seawater intrusion.

The information was overlaid and integrated to obtain a new thematic map for vulnerability assessment based on the new model called RIHM, Eq.6:

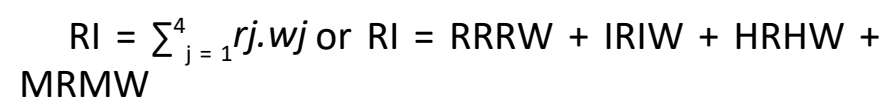

Where $\mathrm{R}, \mathrm{I}, \mathrm{H}$ and $\mathrm{M}$ are the four parameters. $R$ and $W$ are respectively, the rating and weight of each parameter (Figure 9).

RIHM map shows four classes. It depicts different degrees of the aquifer's sensitivity to seawater intrusion along Monastir coastal aquifer. RIHM Index (RI) ranges from less than 109 to 176. The highest class of vulnerability covers particularly the northeastern part, which is high affected by seawater intrusion such as Teboulba. The low vulnerability registered in the southern part. By comparing distribution of $\mathrm{RI}$ to other models $\mathrm{DI}, \mathrm{SI}$ and GI (Figure 3), the distribution of high vulnerability zones is the same in all the maps. While, RI has a clear and logic distribution of the different domains from low vulnerability to very high vulnerability. This map dedicates the success of this model to study the extension of seawater intrusion inland.

\section{*Validation of the RIHM method}

Figure 10 shows the plots of RI against electrical conductivity (EC) along a cross section, and all PCC have been interpreted. They are tolerated to a significant cumulative probability (Cum $p=0.05$ ). Although, Figure 11 shows distribution of TDS in Monastir aquifer system. Indeed, the applied index (IR) is well validated by the field of measurements and chemical analyses. EC is expected to increase with increasing vulnerability. When EC is very high $(>8000 \mu \mathrm{s} / \mathrm{cm})$, the risk of seawater is very high too 


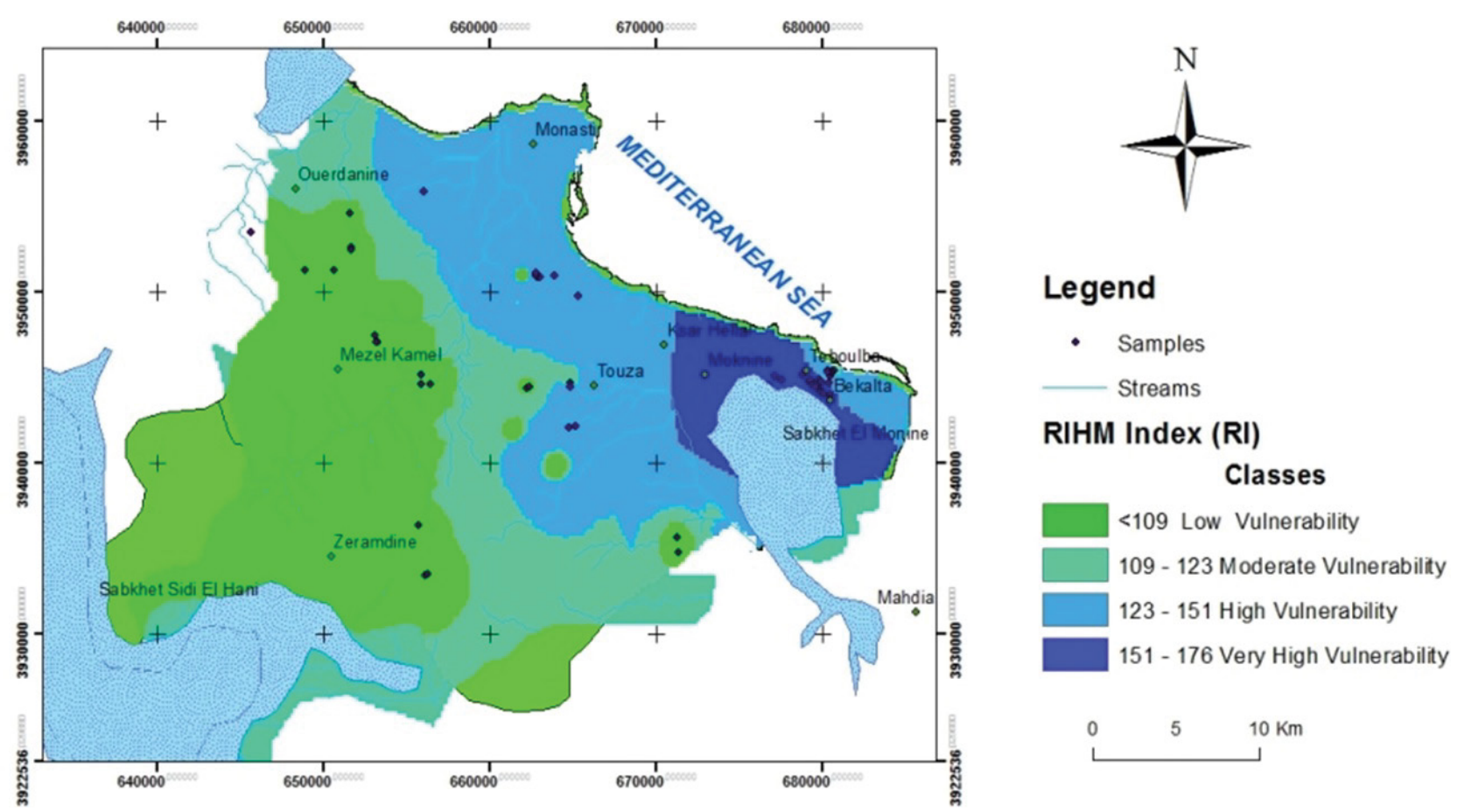

Figure 9: The vulnerability indexes ( $/ \mathrm{v}$ ) map of RIHM for the Monastir aquifer system (Coordinate System NTT: defined by UTM projection system and Clarke 1880, as the local Geodetic reference frame of Tunisia).

\section{Diagram IR vs CE}

Correlation: $r=0,95$
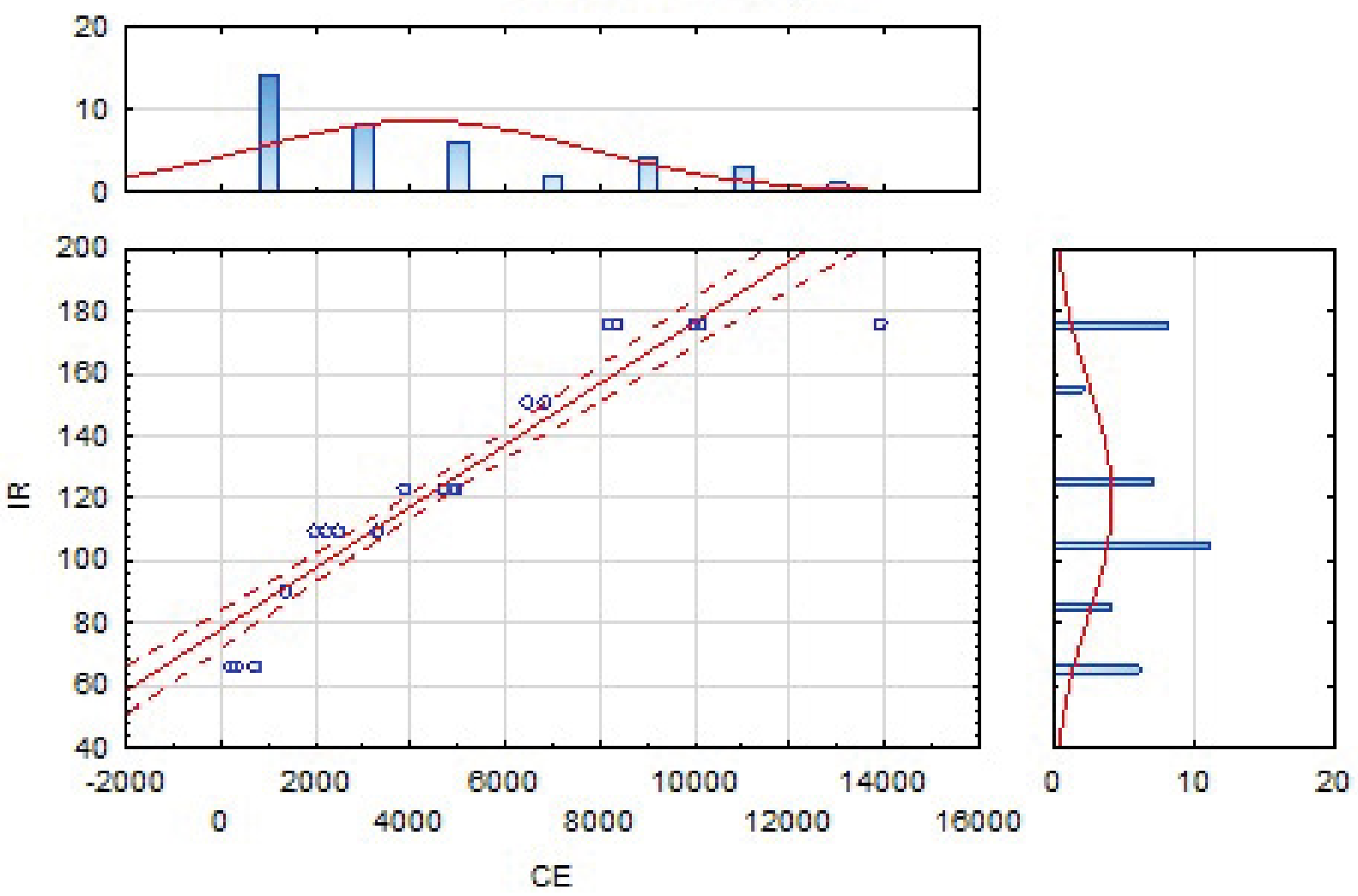

Figure 10: Correlation between the $I R$ and electrical conductivity values (EC) for the study area, all PCC are significant at Cum $p=0.05$. 


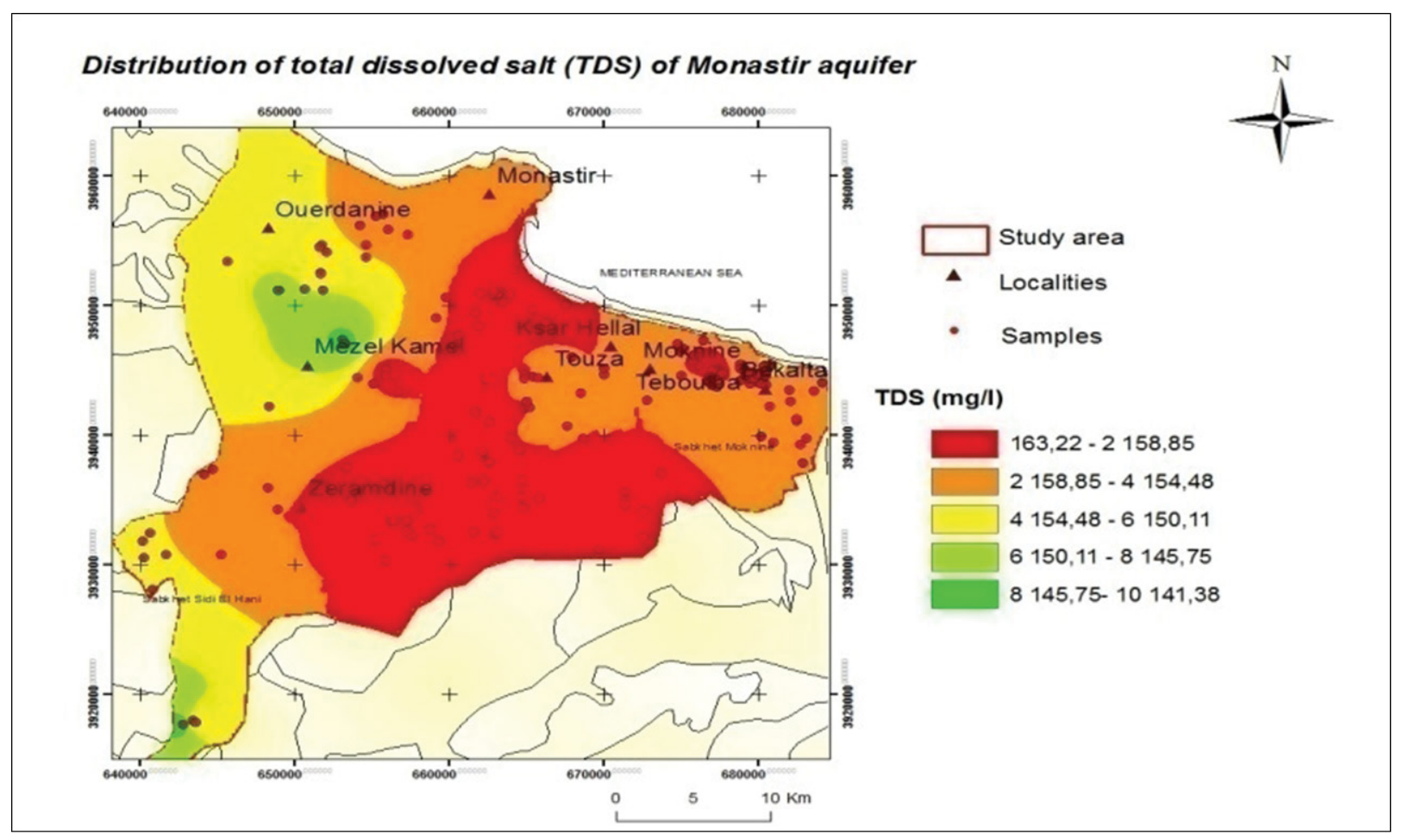

Figure 11: Distribution of TDS (Total Dissolved Salt) in the aquifer system of Monastir, Tunisia.

as well as its index of vulnerability. The high $I R$ is accompanied with a PCC approximately 0.95. And, the IR distribution shows the same distribution of TDS. The high vulnerable areas such as Teboulba have high value of TDS too more than $4000 \mathrm{mg} / \mathrm{l}$. Thus, RIHM has been selected as the optimal model. Seawater intrusion phenomenon extending in Monastir aquifer plain should be taken seriously as a huge hazardous. Therefore, groundwater would become inappropriate even for resistant cultivations in large areas of Monastir's aquifer system. Those Multiple relations between the factors and the seawater intrusion distribution were tested with factor analysis (FA) and multiple regression analysis (MRA).

\section{${ }^{*}$ RIHM method limitations}

Aquifer vulnerability is a relative term used to predict the protection level of groundwater system. All aquifers are vulnerable to some degree. Therefore, RIHM vulnerability model just like other vulnerability models has its limitations, including: (1) RIHM does not account for human activity. Therefore pumping tests with adverse impact on hydraulic conductivity must be assessed separately. (2) The RIHM is an intrinsic groundwater vulnerability method; it never accounts for the contaminant types presented in the surface of the land. (3) The RIHM does not model fate/transport of chemical constituents. (4) Large surface water features are not considered in the RIHM method.

\section{Conclusion}

This study was carried out to assess groundwater vulnerability of aquifer system of Monastir. It is almost an unconfined aquifer formed by MioPlio-Quaternary deposits. In fact, seawater intrusion phenomenon has become irreversible in the plain aquifer of Monastir. This is due to the high permeability (unconfined aquifer), the high hydraulic conductivity $(60 \mathrm{~m} /$ day $)$, the shallow groundwater table $(<8 \mathrm{~m})$, the aquifer thickness $(<10 \mathrm{~m})$ and relatively the low distance separating wells from the sea $(<2000 \mathrm{~m})$. A RIHM method proposed and applied to evaluate the degree of vulnerability for Monastir shallow aquifer system is a simplified subjective and physically based vulnerability method. Its comparison to establish methods shows closer similarity with GALDIT method. The method will be useful in the vulnerability mapping of data lacking areas due to its reduced parameter requirement as compared to other methods. However, its limitation does not reduce its effectiveness in assessing intrinsic aquifer vulnerability that regulates pumping activities that may induce seawater intrusion problems to 
groundwater resources. This new model has been built with the resulted parameters from sensitivity analysis of DRASTIC, SINTACS and GALDIT models. The application of DRASTIC, SINTACS and GALDIT methods and GIS techniques added to hydrochemical analyses of the groundwater are used to evaluate the impact of the increase of salted level, as well as to assess potential seawater intrusion in the study area. Indeed, sensitivity analysis represents a way to identify the causes of the enlargement of these phenomenon inlands. As a result, the extension of seawater intrusion in Monastir aquifer system was related essentially to: Recharge (R) is calculated as the sum of DRASTIC net recharge and SINTACS infiltration parameters, Impact of seawater intrusion $(I)$ is the Revelle ratio $\left[\mathrm{Cl}^{-}\right] /\left[\mathrm{HCO}_{3}^{-} ; \mathrm{CO}_{3}^{2}\right]$, SINTACS hydraulic conductivity of the aquifer $(\mathrm{H})$ and the Mixed-up (M) of the saturated (aquifer media parameter for DRASTIC) and unsaturated aquifer zones (nonsaturated zone media parameter for SINTACS). For validation, RIHM vulnerability index (RI) was well correlated to electrical conductivity (EC) and it has the same distribution as TDS. Consequently, it is an emergency to never neither allow additional wells nor over pumping for the exciting wells in the study area, in order to preserve groundwater resource and reduce environmental pollution hazardous. Accordingly, an attention should be paid to an environmental protection in this area. The southern part of the aquifer will be more suitable for the implantation of potential anthropogenic activities and the northern part should be considered by the managers in order to minimize groundwater contamination by seawater intrusion.

\section{Funding}

Not applicable.

\section{Conflicts of Interest/Competing Interests}

Hydrogeology, GIS, modeling, vulnerability assessment.

\section{Code Availability}

Not applicable.

\section{References}

1. Pulido-Leboeuf $P$ (2004) Seawater intrusion and associated processes in a small coastal complex aquifer (Castell de Ferro, Spain). Appl Geochem 19: 1517-1527.
2. Kouzana L, Mammou AB, Felfoul MS (2009) Seawater intrusion and associated processes: Case of the Korba aquifer (Cap-Bon, Tunisia). Comptes Rendus Geosci 341: 21-35.

3. Ledoux E (2003) Modèles mathématiques en hydrogéologie. Centre d'Informatique Géologique, Ecole Nationale Supérieure des Mines de Paris, LHMRD - 86/12.

4. Carrey R, Rodríguez-Escales P, Oteroa N, Ayora C, Solera A, et al. (2014) Nitrate attenuation potential of hypersaline lake sediments in central Spain: Flowthrough and batch experiments. J Contam Hydrol 164: 323-337.

5. Pedreira R, Kallioras A, Pliakas F, Gkiougkis I, Schuth C (2015) Groundwater vulnerability assessment of a coastal aquifer system at River Nestos eastern Delta, Greece. Environ Earth Sci 73: 6387-6415.

6. Calvache ML, Pulido-Bosch A (1994) Modeling the effects of salt-water intrusion dynamics for a coastal karstified block connected to a detrital aquifer. Ground Water 32: 767-777.

7. Abdelkader Y, Elkbir L, Jacky M (1997) La mise en évidence de l'intrusion marine de la nappe d'El Jadida, Maroc. Hydrochemist 115-122.

8. Najib S, Grozavu A, Mehdi K, Breabăn IG, Guessir H, et al. (2012) Application of the method GALDIT for the cartography of groundwaters vulnerability: Aquifer of Chaouia coast (Morocco). Analele stiintifice ale Universitatii" Alexandru Ioan Cuza" din Iasi-seria Geografie 58: 77-88.

9. Mohammadi Z, Zare M, Sharifzade B (2012) Delineation of groundwater salinization in a coastal aquifer, Bousheher, South of Iran. Environ Earth Sci 67: 1473-1484.

10. Polemio M (2005) Seawater intrusion and groundwater quality in the Southern Italy region of Apulia: A multi methodological approach to the protection.

11.Albinet M, Margat J (1970) Cartographie de la vulnerabilit'e ala pollution des nappes d'eau souterraine. Groundwater Pollution - Symposium Pollution des Eaux Souterraines. IAHS-AISH Publ 103: 13-22.

12.Rahman A (2008) A GIS based DRASTIC model for assessing groundwater vulnerability in shallow aquifer in Aligarh, India. Appl Geogr 28: 32-53.

13.Ghazavi R, Ebrahimi Z (2015) Assessing groundwater vulnerability to contamination in an arid environment using DRASTIC and GOD models. Int J Environ Sci Technol 12: 2909-2918. 
14.Guo H, Wang $Y$ (2004) Specific vulnerability assessment using the MLPI model in Datong city, Shanxi province, China. Environ Geol 45: 401-407.

15.Kumar S, Thirumalaivasan D, Radhakrishnan N, Mathew S (2013) Groundwater vulnerability assessment using SINTACS model. Geomat Nat Hazards Risk 4: 339-354.

16.Luoma S, Okkonen J, Korkka-Niemi K (2017) Comparison of the AVI, modified SINTACS and GALDIT vulnerability methods under future climatechange scenarios for a shallow low-lying coastal aquifer in southern Finland. Hydrogeol J 25: 203-222.

17.Kura NU, Ramli MF, Ibrahim S, Sulaiman WNA, Aris AZ (2014) An integrated assessment of seawater intrusion in a small tropical island using geophysical, geochemical, and geostatistical techniques. Environ Sci Pollut Res 21: 7047-7064.

18.Allouche N, Maanan M, Gontara M, Rollo N, Jmal I, et al. (2017) A global risk approach to assessing groundwater vulnerability. Environ Model Softw 88: 168-182.

19.Sener E, Sener S, Davraz A (2009) Assessment of aquifer vulnerability based on GIS and DRASTIC methods: A case study of the Senirkent-Uluborlu Basin (Isparta, Turkey). Hydrogeol J 17: 2023-2035.

20.Chenini I, Zghibi A, Kouzana L (2015) Hydrogeological investigations and groundwater vulnerability assessment and mapping for groundwater resource protection and management: State of the art and a case study. J Afr Earth Sci 109: 11-26.

21.Akbari GH, Rahimi-Shahrbabak M (2011) Sensitivity analysis of waters at higher risk subjected to soil contaminations. Comp Meth Civil Eng 2: 83-94.

22.(2007) Institut National de la Météorologie, I. Controle de l'évolution climatique de la partie centrale.

23. Castany G, Gobert E-G, Harson L (1956) Le quaternaire marin de Monastir.

24.Khiari N, Atoui A, Khalil N, Charef A, Aleya L (2017) Dynamics of sediments along with their core properties in the Monastir-Bekalta coastline (Tunisia, Central Mediterranean). J Afr Earth Sci 134: 320-331.

25. Hamza $\mathrm{MH}$, Added A, Rodríguez R, Abdeljaoued S, Ben Mammou A (2007) A GIS-based DRASTIC vulnerability and net recharge reassessment in an aquifer of a semi-arid region (Metline-Ras Jebel-Raf Raf aquifer, Northern Tunisia). J Environ Manage 84: 12-19.

26.Napolitano P, Fabri A (1996) Single parameter
Sensitivity analysis for aquifer vulnerability assessment using DRASTIC \& SINTACS. Hydro GIS 96: 559-566.

27. Voudouris K, Kazakis N, Polemio M, Kareklas K (2010) Assessment of intrinsic vulnerability using the DRASTIC model and GIS in the Kiti aquifer, Cyprus. European Water 30: 13-24.

28. Baghapour MA, Nobandegani AF, Talebbeydokhti N, Bagherzadeh S, Nadiri AA, et al. (2016) Optimization of DRASTIC method by artificial neural network, nitrate vulnerability index, and composite DRASTIC models to assess groundwater vulnerability for unconfined aquifer of Shiraz Plain, Iran. J Environ Health Sci Eng 14: 13.

29. Kaliraj S, Chandrasekar N, Peter TS, Selvakumar S, Magesh NS (2015) Mapping of coastal aquifer vulnerable zone in the south west coast of Kanyakumari, South India, using GIS-based DRASTIC model. Environ Monit Assess 187: 4073.

30.Civita M (2010) The combined approach when assessing and mapping groundwater vulnerability to contamination. J Water Resour Prot 2: 14-28.

31. Hiscock K, Lovett M, Brainard A, Parfitt JP (1995) Groundwater vulnerability assessment: Two case studies using GIS methodology. Quarterly Journal of Engineering Geology and Hydrogeology 28: 179-194.

32. Recinos N, Kallioras A, Pliakas F, Schuth C (2015) Application of GALDIT index to assess the intrinsic vulnerability to seawater intrusion of coastal granular aquifers. Environ Earth Sci 73: 1017-1032.

33. Oroji B (2019) Groundwater vulnerability assessment with using GIS in Hamadan-Bahar plain, Iran. Appl Water Sci 9: 196.

34.Javadi S, Kavehkar N, Mohammadi K, Khodadadi A, Kahawita R (2011) Calibrating DRASTIC using field measurements, sensitivity analysis and statistical methods to assess groundwater vulnerability. Water Int 36: 719-732.

35. Chachadi A, Lobo Ferreira JP (2005) Assessing aquifer vulnerability to sea-water intrusion using GALDIT method: Part 2 - GALDIT Indicators Description. The Fourth Inter-Celtic Colloquium on Hydrology and Management of Water Resources, Guimaràes, Portugal.

36.Essefi E, Touir J, Tagorti MA, Yaich C (2014) Geodynamic Framework of saline systems in Eastern Tunisia: Saline depressions inherited from the Triassic intrusions and/or the Messinian salinity crisis. ISRN Geol 2014: 1-13. 
37. Dlala Mahmoud, RebaiS (1994) Relation compressionextension Miocène supérieur à Quaternaire en Tunisie: Implication sismotectonique. Comptes rendus de l'Académie des sciences. Série 2. Sciences de la terre et des planètes 319: 945-950.

38.Dlala M (1995) Evolution géodynamique et tectoniques superposés en Tunisie: Sur l'implication tectonique récente et la sismicité. Thèse d'Etat, Université de Tunis El Manar, Tunisie.
39.Aller L, Bennett T, Lehr J, Petty R, Hackett G (1987) DRASTIC: A standardized system for evaluating ground water pollution potential using hydrogeologic settings. US Environmental Protection Agency, Report 600/2-85/018, Washington.

40.Saidi S, Bouri S, Dhia HB (2013) Groundwater management based on GIS techniques, chemical indicators and vulnerability to seawater intrusion modelling: application to the Mahdia-Ksour Essaf aquifer, Tunisia. Environ Earth Sci 70: 1551-1568. 